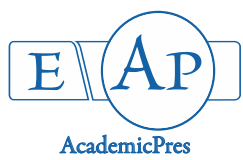

Wicaksono A and Cristy GP (2021)

Notulae Scientia Biologicae

Volume 13, Issue 2, Article number 10929

DOI: $10.15835 /$ nsb13210929

Review Article

\title{
Xenobiology: An expanded semantical review
}

\author{
Adhityo WICAKSONO*, Ghea P. CRISTY
}

Division of Biotechnology, Genbinesia Foundation, Jl. Swadaya Barat no. 4, Gresik61171, East Java,
Indonesia; adhityo.wicaksono@gmail.com (*corresponding author); christy.ghea@gmail.com

\begin{abstract}
The definition of "xenobiology" has gradually shifted from the study of the foreign, estranged life forms potentially existing in outer space to the study where the natural and synthetic life are involved. The natural concept of xenobiology governs the unseen, hypothetical life on the outer space, and the hidden life with completely different biochemistry on Earth. The life on the outer space might possess different way to harvest energy from the one on Earth. The hidden life on Earth, or the "Shadow Biosphere" might rose from completely different way of creation and evolution on Earth, which lead to its complete difference from the known biosphere. The newest concept of xenobiology involves synthetic life, built with unnatural base pair of the nucleic acid, with analogous or xeno nucleic acid (XNA), has a synthetic genome which capable of selfreplicating or enables the synthetic cell to self-replicate, or even possesses a synthetic physiological pathway. By understanding the broad spectrum of xenobiology, in both natural and synthetic concepts, we can expand our view on how life might develop into a completely estranged system, which is different from anthropocentric view of life available around us on Earth. From these perspectives, we might understand how life evolved by evolving it synthetically.
\end{abstract}

Keywords: estranged life; origin of life; shadow biosphere; speculative biology; synthetic life

\section{Introduction}

The term 'xenobiology' comes from the Greek words xenos, bios, and -logia. Bios means 'life' and -logia means 'the study of-', hence 'biology' means the study of life. Xenos ( $\xi \varepsilon v \circ \varsigma)$ has many meanings: foreign, outsider, and strange (Stavropoulos and Hornby, 2008). Therefore, xenobiology can be translated as the study of foreign and extrinsic life. Later in 2020, xenobiology is defined as the science of estranged life forms (Budisa et al., 2020).

In its early development, "xenobiology" (Oxford Dictionary, 2016; http://www.oxforddictionaries.com) was used as a term which concerns life from outer space and synonym to astrobiology. The term was mentioned around 1950s in the literatures of Robert A. Heinlein. A similar word can be found in medical use. The word "xenobiotic" (Merriam-Webster.com, 2016; http://www.merriam-webster.com) is defined in 1965 as a chemical compound (as drug, pesticide, or carcinogen) that is foreign to a living organism (Merriam-Webster, 2016). However, everything outside the known sign of biological life itself supposedly could be mentioned as a xenobiotic entity as well. Later, the term was used by Schmidt (2010) to include the synthetic life created in a laboratory, which potentially possesses genetic material or biological system different from the ordinary

Received: 16 Mar 2021. Received in revised form: 05 Jun 2021. Accepted: 09 Jun 2021. Published online: 23 Jun 2021.

From Volume 13, Issue 1, 2021, Notulae Scientia Biologicae journal uses article numbers in place of the traditional method of continuous pagination through the volume. The journal will continue to appear quarterly, as before, with four annual numbers. 
biological system on Earth. In the end, whether the life is naturally-occurring or even synthetic, common and estranged, it has to obey the definition of life as we know it, i.e. the general capability of the entity to perform energy transfer (metabolism), growth, adaptation to environment, and reproduction (Schulze-Makuch and Irwin, 2018).

Framing through this perspective, the term "xenobiology" thus covers many concepts of foreign life which were different and unique from what were generally found on Earth. The concept ranged from purely speculative biology to known part of astrobiology, even extending to the microbiology of extremophiles and the engineered modern synthetic biology. In this case xenobiology governs the estranged life located in the field of the unknown (Figure 1). The life could be natural but somewhere in space with completely different constitution from biophysics, biochemistry. Alternatively, the life adheres to the other contexts in biology; it might be previously undiscovered on Earth, or something that emerges from synthesized process (Popa, 2010). In this paper, those coverages can be classified as:

1. Natural Xenobiology - Xenobiology which covers the foreign life which might occurred naturally, this concept is separated into:

a. Exo-Xenobiology - Xenobiology concerning the study of hypothetically or speculative life in space because no foreign life has been found yet

b. Terran Xenobiology - Xenobiology concerning the study of hidden life on Earth with different biosystem than life as we know it

2. Synthetic Xenobiology - Xenobiology concerning engineered or synthetic life on Earth.

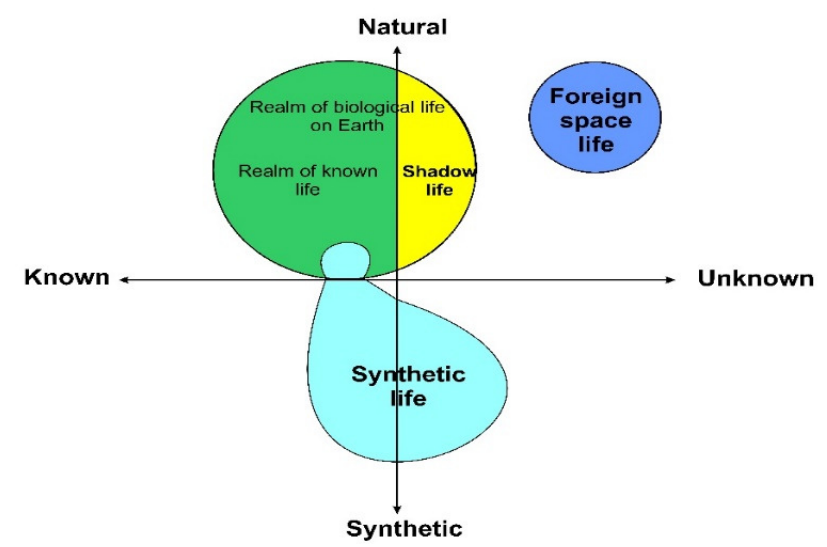

Figure 1. The concept of life with known body of life or life as we know it vs. the estranged xenobiological components between two axes of known-unknown aspect and natural-synthetic aspect

The common problem in astrobiology is more toward the place and condition in space that suits the origin of life and allows it to evolve, as opposed to the prediction of how life itself could emerge differently in unlimited possibilities. As life in space has not yet been found and revealed, the depiction of life in xenobiology can only be predicted under speculative biology approach, using both art and science as basic references to picture life beyond Earth in any possible scenario. Although this approach sounds very science fiction materialany idea can sound fictitious when elaborated in detail-it could seriously become the "new reality" in 'pataphysical' philosophy, for 'pataphysics' itself is a philosophy of science of imaginary solutions beyond metaphysics (Hugill, 2012). Apart from the space, the life on Earth itself is considerably unique in the universe. This is due to the precise condition needed for the emergence of early life. Living organism in the universe became so rare, thus the phenomenon became known as "rare earth hypothesis" (Ward and Brownlee, 2000). The other argument is the idea of "the great filter" in the context of Fermi's paradox that refers to gap that prevents a non-living matter into a living organism and an even more complex life (e.g. from an ideal star system to self-replicating molecules to simple unicellular life and beyond), and this idea hypothesized that the life out 
there is rare because possibly they, 1) has not yet reached the complexity (which means that we are probably the first to reach complexity; the other alien life is behind the gap that leads us to our current progress), or 2) have been eliminated (which means that in some point the alien race has become significantly advanced and they became extinct due to the resource scarcity, civil war, etc.; the gap is in front of our current progress) (Hanson, 1998).

This led to the idea that the evolution of life is a matter of the evolving species' political views, whether a species agree to take a step or disagree, and this possibility may determine the future of a species if they will progress to evolve or become extinct (Hawking, 1996). In the end, it is greatly unknown if there are other life, whether they are simple or complex, that has passed the great barrier and survive as a xenobiological entity out there on space and even completely hidden on Earth.

The latter definition offers xenobiology as the "creation" of exotic life in laboratory using synthetic biology. The process includes the introduction of essential metabolic pathways, the novel nucleobases other than the four common bases, or the creation of nucleic acids with different sugar backbones which are also known as xenobiotic nucleic acid (XNA). This XNA promises barrier of biosafety (biocontainment) that prevents the synthetic system from interacting with common genetic system made by DNA and RNA, thus eliminating chances of genetic pollution (Schmidt, 2010).

This essay will attempt to discuss various concepts of xenobiology. The focus will be directed toward the variations of xenobiology coverage and how the term applies in the context of biology. The author hopes that the classification made could help to understand the differences between each context in xenobiology and every other branch of biology. In this respect, we can understand a wider perspective on defining life and how its origin is not limited only to the biogenesis on Earth that occurred billions of years ago. Additionally, and specifically for xenobiology as a sub-field of synthetic biology, by understanding the wider meanings in xenobiology, the field can be better implemented into teaching, i.e. so students can fully understand the connections between concepts of natural vs. synthetically-made estranged life forms.

\section{The naturally occurring xenobiological system}

\section{Xenobiology as an extension of astrobiology}

According to Mix (2009), "xenobiology" means the study of alien life, and it differs from astrobiology as astrobiology more focused on interdisciplinary field (such as astronomy, physics, planetary science, geology, chemistry, biology, and more) to describe life that possibly occurred in space. Astrobiology is defined as study of life throughout the universe, and the term itself was used in 1941 by L. J. Lafleur and in 1953 by Gavriil Tikov (Darling and Schulze-Makuch, 2016). Astrobiology focused on finding conditions in the outer space that support life and places that might support evolution of complex life and not only study of the origin of life.

There is also a term called "exobiology" that mentioned life in space. According to Merriam-Webster Dictionary (2016), "exobiology" is defined as a branch of biology concerned with the search for life outside the Earth, including the effects of extra-terrestrial environments on living organisms. This term is firstly used in 1960. The word exo $(\varepsilon \xi \omega)$ in this regard comes from Greek that means 'outside' (Stavropoulos and Hornby, 2008). The term of exobiology was coined by Joshua Lederberg in 1960 "to distinguish this aspect of space biology - the evolution of life beyond our own planet" and he considers it synonymous with astrobiology (Darling and Schulze-Makuch, 2016). The old term has evolved to look upon the living system extended from Earth to the realm of the outer space as exobiology. The wider scope now includes space biology, or the study of how the condition during space flight and in the extra-terrestrial environment (Editors of the American Heritage Dictionaries, 2011).

The renewed understanding of "exobiology" now covers all life outside the Earth; the life on Earth that were carried outside into space (by using space modules) as we learn in space biology, something that possibly occurred on the outer space by using approach of knowledge as we know it in astrobiology, into something 
speculatively and completely estranged to Earth life in xenobiology (Figure 2). The intersections between the bubbles in Figure 2 refers to the body of shared knowledge between the bubbles, and further apart, the knowledge is becoming more exotic or eccentric towards the unknown.

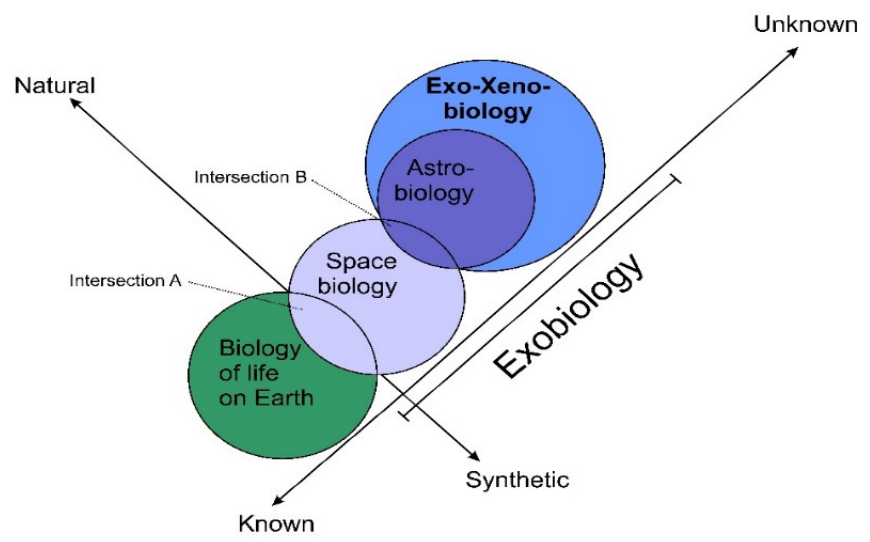

Figure 2. Concept of life beyond Earth or exobiological system

The similarities to Earth life drift away as it goes further against Earth's known biological system (from biology to xenobiology). Intersection A refers to the similarities shared when the biological organism is taken into space and later adapted. Intersection B refers to the similarities of characteristics of biological organism when taken to space then adapted even further to any condition similarly described in astrobiology. As not all phenomenon in space has been known, the depiction of speculative life in astrobiology may be both life as we know it and as we don't know it. The realm of life as we don't know it in the unknown depth of space is covered within exo-xenobiology. All, however, are still located in the natural system.

Space biology concerns with the event when any life from Earth is brought into the condition of space environment, e.g. microgravity, high radiation, dehydration, etc. For example, regarding gravity, the study focused on how changes in gravity affect biological system, which can be done both on Earth as ground-based experiments or in space station/modules. Ground-based experiment uses instruments to replicate the condition on space, for the example using clinostat to minimize the influence of gravity or centrifuge for manipulation of the centre of gravity pull (Clément and Slenzka, 2006). Further away from life on Earth, astrobiology is a field of interdisciplinary science focusing on elaborating condition on location in space (planets, satellites, asteroids, etc.) that potentially supports conditions like early Earth that build complex life. The challenge in this scenario is to find exoplanetary system with terrestrial planet (Earth-like planet) that orbits the host star's habitable zone so it will be suitable to known life (Impey, 2011). In some ways, astrobiology uses the definition of life as we know it to speculate life on the known region of celestial body in space. However, there are also speculation of life as we don't know it (Schulze-Makuch and Irwin, 2018) and here, part of astrobiology about life in the unknown region of the deep space where physics can be also unknown, thus pushing the life estranged further into the deeper realm of speculative biology, there is xenobiology or can be specifically coined here as exo-xenobiology.

Although exo-xenobiology tends to be speculative-technically because life beyond Earth has not been found so far, this field challenges scientists to 'create' and bring the completely strange-from-Earth life using available scientific data. Space hosts various environments from extremely hot, to frozen, to near-absolute zero temperature and different chemical abundant on each exoplanet depending on the type and age of the star it orbits to (Lodders, 2010). Outside of 20 proteogenic/genetically encoded amino acids, there are more than 140 amino acids found in natural protein (Ambrogelly et al., 2007). In space, there are 70 amino acids found within 14,000 molecular compounds in the Murchison asteroid detected using spectrometry (Schmitt-Kopplin et al., 2010; Walton, 2010). This amount is roughly one-thirtieth from about 500 amino acids discovered in nature (Wagner and Musso, 1983). The Murchison asteroid amino acid includes proteogenic amino acids (among the 
20 amino acids), e.g. glycine, alanine, and glutamic acid, and the unusual amino acids, e.g. isovaline and pseudoleucine (Kvenvolden et al., 1970). Moreover, trace of nucleotides, uracil (purine that also available in the RNA of organisms) and xanthine (purine found in metabolic pathways) were also found (Martins et al., 2008). The challenge in finding life in space may be relative to the anthropocentric view on how life could be on Earth, which were carbon-based life. Out in space, carbon might not abundant and other elements like nitrogen, boron, and silicon might be the hypothetical elements that composed life (Darling and SchulzeMakuch, 2016). The undiscovered life in space might also harness their own method to extract energy, while on earth autotrophs thrive on light (photoautotroph) and chemical redox electron transfer (chemoautotroph).

According to Schulze-Makuch and Irwin (2018), there are possibilities of the other energy sources for life as we do not yet know (Figure 3). These possibilities of energy sources are consistent to the fact that organisms are "open systems" that are harnessing changes in their environment to reduce their own entropy on the cost of the environment and maintain homeostasis.

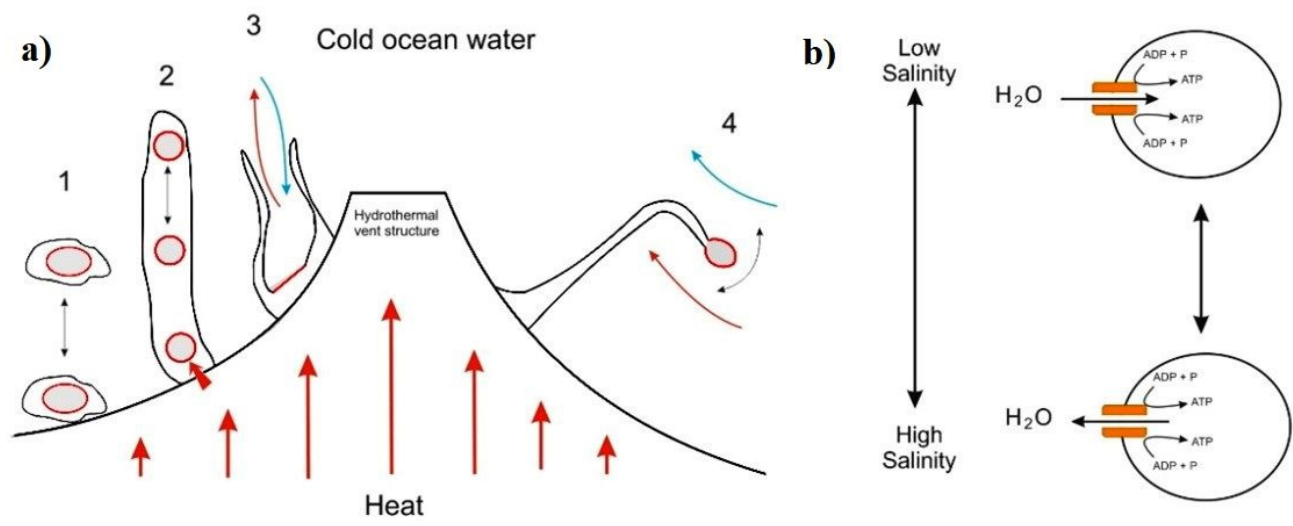

c)
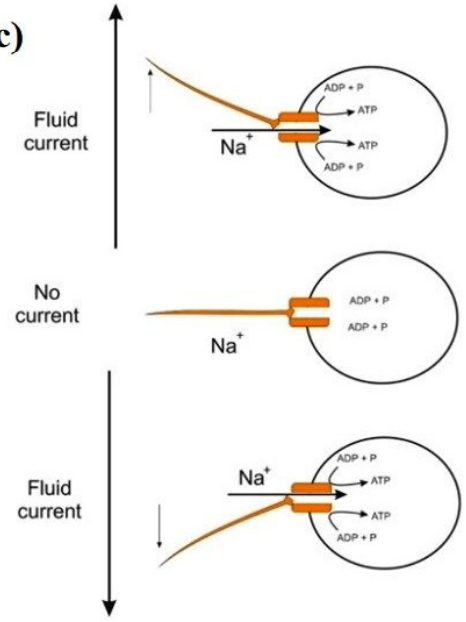

d)

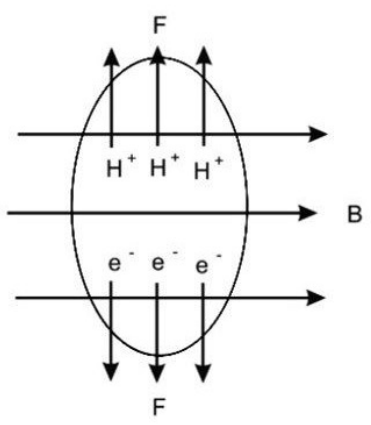

(1)

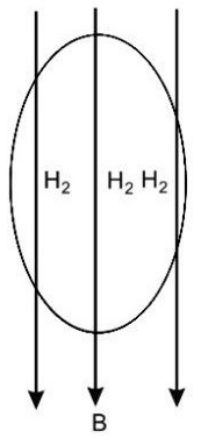

(2)

Figure 3. Hypothetical concept of organisms using other than light and chemical redox process to harvest energy: using change in cellular-molecular conformations by heat (a), using in-out flow of water by osmotic change (b), using kinetic-guided system in membrane to allow ion transfer (c), and using magnetic field (the field shown by B) and Lorentz force (shown by F; d). Details: (1a) mobile cellular thermotroph, (2a) sessile thermotroph with mobile vacuole to move in different heat gradient, (3a) sessile thermotroph with heat convection cavity, and (4a) sessile thermotroph with moveable body appendage to follow heat gradients

Note: Red arrows - high temperature heat gradient, Blue arrows - low temperature heat gradient. Figure remade and inspired by Schulze-Makuch and Irwin $(2002,2018)$. 
The details of the speculative autotrophs by Schulze-Makuch and Irwin (2018) as follows:

1. Thermal energy harvester (thermotroph) extracts energy by transfer of heat stored in their cytoplasm or vacuoles (Figure 3a; Muller and Schulze-Makuch, 2006). The heat gradient affects the membrane molecular conformation and turned into energy by specific protein. The organism might be mobile as it moves away and closer to the heat source (Figure 3a-1), sessile but possesses internal mobile heat transferring vacuoles (Figure 3a-2), sessile with heat convection cavity (Figure 3a-3), or sessile but moving its extrusion of the body by the heat currents (Figure 3a-4).

2. Osmotic gradients harvester (osmotroph) uses in and out water flow due to osmotic pressure changes to generate energy (adenosine triphosphate or ATP molecules) with aid of its membrane protein channel (Figure 3b).

3. Kinetic harvester (kinetotrophs) uses specifically developed protein channel with flagellum/cilia-like transmembrane protein acts as channel guard and kinetically driven (by fluid flow) lever protein that allows the mobilization of specific molecules into and from the cell that drives synthesis or phosphorylation of ATP (Figure 3c; Schulze-Makuch and Irwin, 2002).

4. The most unusual condition is the magnetic field harvester (magnetotrophs) that uses Lorentz force and magnetic field to manipulate hydrogen atoms to move as protons that drive ATP creation or as hydrogen molecules (Figure 3d, 1-2; Schulze-Makuch and Irwin, 2018).

It was previously hypothesized by Kuznetsov (1956) as a theoretical method to capture and metabolise ionizing radiation and it is also stated by Schulze-Makuch and Irwin (2018) as well. In the 1990s, it was discovered that there were radiotrophic fungi found in the remains of Chernobyl Nuclear Power Plant (Zhdanova et al., 1994; Zhdanova et al., 2004) and later speculated that the fungi used melanin as tool to utilize the radioactive ionizing radiation into energy via energy transduction as the radiation alters the melanin electronic properties and resulted in growth enhancement of the fungi (Dadachova et al., 2007; Dadachova and Casadeval, 2008; Malo and Dadachova, 2019). Dadachova et al. (2007) filed a patent (number US8652827B2) for possible alternative energy utilization process using melanin for radiosynthesis, described as the electron transfer pathway between sets of melanin molecules into antenna complex, then into reaction centre to produce ATP molecules in analogue to existing photosynthesis light-dependent reaction process in chloroplast organelle and photosynthetic bacteria.

Other speculation in exo-xenobiology relates to possible life that dwells in gas giant like Jupiter, like proposed by Carl Sagan (Sagan and Salpeter, 1976). Many other predictions of life can be scientifically explained as many possibilities occur in the depth of space. In the distant future, learning these possibilities might open some ways in finding the best method for us to harvest unlimited renewable energy from space to support ideal extra-terrestrial colonization for humanity.

\section{Xenobiology and study of hidden life on Earth}

Other than space, it is also possible that the xenobiology system lies unknown, hidden on Earth as "Terran-xenobiology". There are many theories about how life emerged on Earth. One theory called panspermia described that life could be originated from space via bombardment of space objects like meteorites or comets towards the early Earth (Arrhenius, 1903 cit. Horneck et al., 2001). According to this speculation, all life on Earth might be considered "alien" in origin, as all constituents of life are thought to come from the deep space. However, from many scattered "seeds" of life, it is possible that some reside on Earth on a place with extreme environments. There is possibility of hidden life evolved in completely distinct way from the life we know, making it fully estranged and invisible from the surface life on Earth as we had understood. The concept of the biosphere of hidden life was coined as shadow biosphere (Cleland and Copley, 2005). There is also a hypothesis called "the second genesis" implying there were other processes that build life (biogenesis) on Earth outside the one that build to the current life on Earth; those processes probably occur prior to or later than our known biogenesis (Davies and Lineweaver, 2005). The problem is, we do not even understand yet about the whole picture of biogenesis. 
Existence of hidden life in extreme places on Earth could be amongst billions of the identified biosphere of life in taxonomy (Figure 4), which might further cause the shadow life to be extremely hard to find. The diagram in Figure 4 shows that shadow biosphere is located within the known biosphere. This is due to the shadow life with completely different system biology might be similar or even close by the genome if it could be identified. In term of possible ecological relationship, however, the shadow and regular biosphere could be ecologically completely separated, ecologically integrated, or biochemically integrated (Davies et al., 2009).

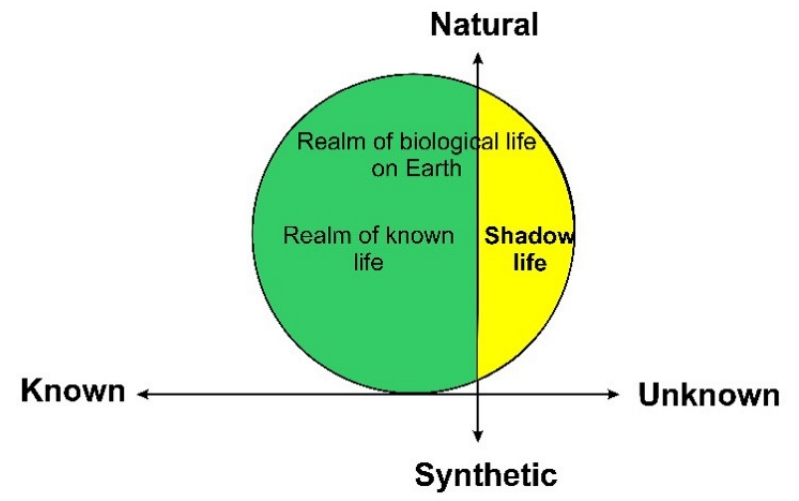

Figure 4. Shadow biosphere concept depicted as an estranged life hidden amongst the Earth biosphere

Until today, the possible and closest way to find the estranged hidden life on Earth is by unravelling the mysterious realm of the extremophile organisms. Microbial extremophiles sometimes appear very unfamiliar. For example, there is halophilic archaea called Haloquadratum walsbyi that possesses a square morphological shape and flat cross-sectional shape (Stoeckenius, 1981). There is not much detail available yet for this archaeon. Another one is Deinococcus radiodurans, known as the most resilient organism on Earth due to its ability to survive cold, dehydration, radiation, vacuum, and acid. D. radiodurans one key to survival is its RecA protein that contributes in DNA repair underexposure to extremely high radiation (Kim and Cox, 2002). Then there are also Monocercomonoides sp., a eukaryotic single-cell protist and a multicellular cnidarian, Hanneguya salminicola with no mitochondria (Karnkowska et al., 2016; Yahalomi et al., 2020). Previously in 2010, Halomonas bacterium strain GFAJ-1 was thought to be able to withstand high quantity of arsenate that normally toxic to organisms. It was stated that the organism was able to substitute phosphate molecules with arsenate during phosphate starvation up to placing it as phosphate substitute in the DNA nucleotides (WolfeSimon et al., 2011). However, later studies refute the claim as the bacterium is basically arsenate-resistant but still depends on phosphate as no arsenate residual is found in the DNA of GFAJ-1 (Erb et al., 2012; Reaves et al., 2012).

Unlike exo-xenobiology that applies to exobiology concept, Terran-xenobiology approach on Earth is simply referring to hidden life that lives with completely different biochemistry or metabolism and even new perspectives on how life can be evolved. The possibility to find more of this kind of estranged life is small, but the not impossible. New discoveries of estranged life on earth would complete missing links in our current understanding of the evolution of life, e.g. how the largest individual flower on Earth, the parasitic plant Rafflesia, is considered one of the most complex plant life yet it has greatly reduced tissue and organ (Nikolov et al., 2014; Mursidawati et al., 2019) and this may rise question if life in space or hidden on Earth could be systematically complex yet structurally simple. In addition, the estranged metabolisms found in the creatures could also be potential in solving biology-related challenges on earth, as some useful unique halophilic enzymes are discovered in the studies of Haloferax volcanii for its use in bioremediation and biotechnology (Krzmarzick et al., 2018; Haque et al., 2020). 
As the advances in xenobiology progressed, the laboratory testing to simulate or to synthesize the "new" life leads to the third concept of xenobiology: It is a life built by humans themselves using state-of-the-art synthetic biology and bioinformatics. Therefore, it can be coined as synthetic-xenobiology.

\section{The synthetically emerging xenobiological system}

The newest emerging concept of xenobiology comes as the sub-field of synthetic biology. This new field of study aims to understand the origin of life by trying to create a new type of life as we do not know it, as it never existed before. However, instead of searching, this approach of synthetic-xenobiology pushes the known life into the limit of the unknown (hence "synthetic alienation" as coined by Kubyshkin and Budisa (Kubyshkin and Budisa, 2017). By trying to understand xenobiology from the scope of biotechnology, we can understand how life became so complex by trying to mimic the condition of early life on Earth when life was formed. In the other word, creation of the new life through deconstructions of the existing one. Xenobiology, in this case, emerged as a new part of synthetic biology, where synthetic biology itself rose from genetic engineering. The aim is to create, and later learn about, organisms which possess completely different chemical makeups to overtake the already existing natural functions in life, or to create new components and motifs (Kubyshkin and Budisa, 2017).However, as this approach of xenobiology is man-made, the concept is intersected to the known natural system via simpler genetically modified organism, then to the life as result of synthetic biology, toward the currently developed product of synthetic xenobiology, and finally in the unknown region - the future of the synthetic xenobiology life which remains unpredictable and unknown by us (Figure 5).

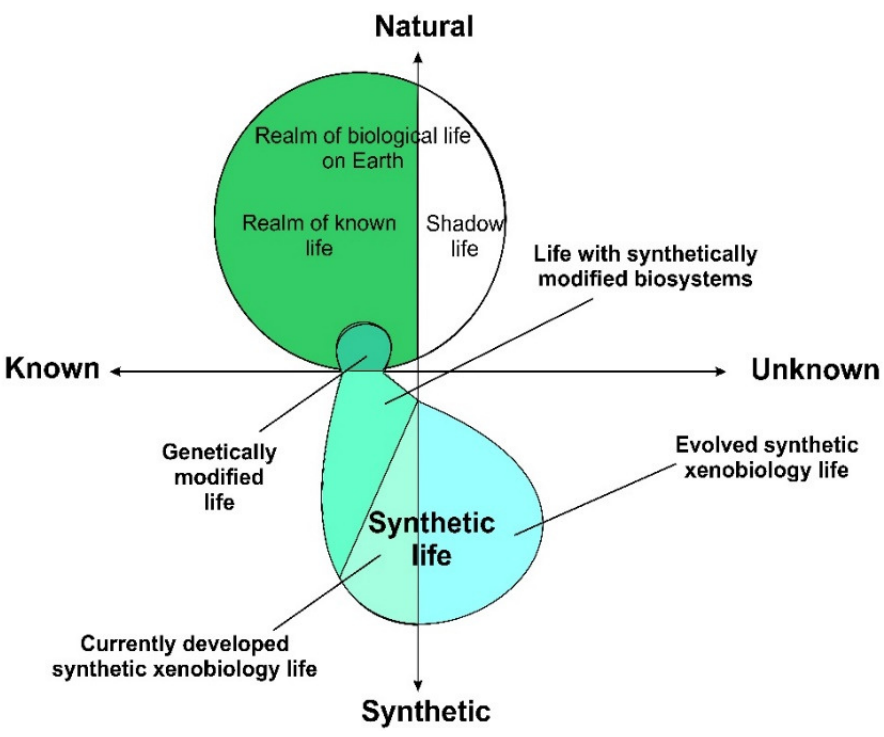

Figure 5. Natural life and emergence of synthetic life

The section that overlaps with Earth biosphere is the natural life with simpler concept of genetic modification. Further away from the natural system is the life with modified biosystems/biological pathways using synthetic biology approach and the currently developed synthetic xenobiology life. Then, crossing into the realm of the unknown is the evolved, future xenobiology life which remains unpredictable.

Genetic engineering is a fundamental tool in biotechnology. The process highlights the ability of each gene to code a specific protein; thus, the gene could be moved from one organism to another. In synthetic biology, genetic engineering is performed in even more complex way: By altering multiple genes to change specifically desired biological systems, e.g. biosynthetic pathways. In more complex application, syntheticxenobiology spawned from synthetic biology as it changes common natural traits in biological system into 
something new via alteration, e.g. changing multiple biological systems, adding novel nucleotides into nucleic acids, synthesis of de novo protein using uncommon amino acids, and creation of nucleic acids with distinct sugar backbones or also known as xenobiotic nucleic acid (XNA) (Schmidt, 2010; Pinheiro et al., 2012).
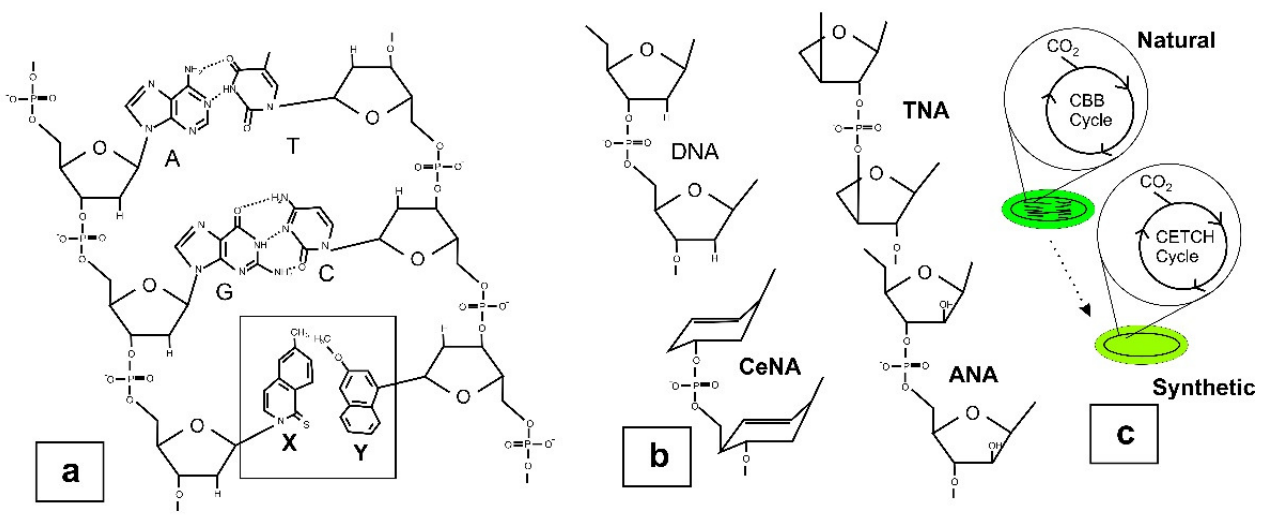

Figure 6. Some examples of possible studies in the synthetic-xenobiology: (a) implementation of uncommon base pairs $(\mathrm{A}=$ adenine; $\mathrm{T}$ = thymine; $\mathrm{G}=$ guanine; $\mathrm{C}=$ cytosine; and the synthetic bases: $\mathrm{X}$ $=\mathrm{d} 5$ SICS; $\mathrm{Y}=\mathrm{dNaM}$ ), (b) engineering the uncommon sugar backbone for XNA (DNA = deoxyribose nucleic acid, the natural nucleic acid involved in heredity; and the synthetic sugar backbones: TNA = threose nucleic acid; CeNA = cyclohexitol nucleic acid; ANA = arabinose nucleic acid), and (c) creation of foreign biosynthetic pathway. The base structure in (a) is inspired by Galindo-Murillo and BarrosoFlores (2017), (b) is by Pinheiro et al. (2012), and (c) by Miller et al. (2020).

There are many types of application in synthetic-xenobiology (Figure 6). The process of biosynthetic pathway engineering can be performed, e.g. introduction of a carbon fixating photosynthetic pathway (like Calvin-Benson-Bassham cycle found in autotrophic organisms) into heterotrophic organism like Escherichia coli to fix carbon dioxide and turning it into sugar (Antonovsky et al., 2016). Another example is the creation of synthetic chloroplasts with a crotonyl-CoA/ethylmalonyl-CoA/hydroxybutyryl-CoA (CETCH) cycle instead of the existing Calvin cycle to improve its carbon fixation efficiency (Miller et al., 2020). Although the concept remained close to synthetic biology because the metabolic system of Calvin cycle already exists in nature, the creation of carbon fixating $E$. coli is still introducing something new. Moreover, it is originally unavailable in nature and conforms to the estranged philosophy in xenobiology. Introducing of new nucleotides to extend the existing genetic alphabet is a way further from the commonly available ones. Adding new nucleotides might increase potential to synthesize new protein with new polypeptides. One of the studies was using novel nucleotide pair, $\mathrm{dNaM}$ and d5SICS (Malyshev et al., 2014). Originally, combination of four current nucleotides can encode 20 amino acids from 64 codon combinations ( $4^{3}$ combinations, as each codon contains 3 sets/triplet set of all 4 nucleotides), and now with the addition of 2 nucleotide pairs, it is possible to synthesize more uncommon amino acids using now-improved 216 codon combinations ( $6^{3}$ combinations, now for the triplet set, 6 nucleotides can be used).

The word of xenobiotic nucleic acid or xeno nucleic acid or XNA was first mentioned by Herdewijn and Marlière (Herdewijn and Marlière, 2009; Chaput and Herdewijn, 2019). The XNA is synthesized by transfer from naturally occurring nucleic acid via artificially-mutated polymerase enzyme (Taylor et al., 2015). XNA itself is a group of various nucleic acids other than DNA or RNA which might cover varieties of backbone sugars other than ribose and deoxyribose, e.g. hexitol nucleic acid (HNA), arabinonucleic acid (ANA), 2'fluoro-arabinonucleic acid (FANA), cyclohexitol nucleic acid (CeNA), peptide nucleic acid (PNA), and more (Pinheiro et al., 2012). These nucleic acids are capable to evolve into self-catalysing molecules like XNAzymes and as aptamers/ligands, and it may be useful in therapeutic purpose because most of XNAzymes are invisible, from nuclease enzymes that interact and break down DNA and RNA in the natural living system (Pinheiro et 
al., 2012; Taylor and Holliger, 2015). Once in vivo tests are done, combining XNA with unnatural nucleotide pairs may give birth to xenobiologic living system with nucleic acid other than DNA and RNA, and so far, the closest study to in vivo that were made is by Csibra et al. (2020). In the study, they developed a reporter gene platform that functions by expressing a bacterial cell enzyme display of phi29 DNA polymerase and T4 DNA ligase. This reporter system can be used for screening and engineering the low affinity ligands and enzymes by directed evolution. As XNA has low affinity to the existing system consists of natural nucleic acid like DNA and RNA, this type of cell display is suitable to utilize in development of XNA molecular biology tools. This synthetic-xenobiotic living system is promising as a biosafety tool that prevents genetic pollution, considering most XNA system cannot interact with DNA-RNA system unless via specific mutant/engineered polymerases or enzymes (Schmidt, 2010), and would work as alternative tool for genetic engineering to the public might be an answer to the long-standing debate over benefits and potential risks of genetically modified organisms (GMO) to humanity (Marris 2001, Karalis et al., 2020). Nonetheless, because of pre-existing issues in DNAbased GMO (e.g. genetic contamination, allergenic risk, and antibiotics resistance), it would take more time and it will still be challenging to build positive public reception towards the XNA technology despite its biosafety, especially in the field of food and crops (Hielscher et al., 2016; Karalis et al., 2020). In this context, the public show more acceptance of GMO in medical application rather than GMO in food and crops because drugs, before released to market, have to be tested through preclinical trials. Moreover, not all people would consume the drugs, as it is only given to the targeted portion of population with careful medical assistance, diagnosis, and prescription. Compared to food, without the same precautionary and transparency of information, food will be subjected to everybody despite age and health conditions (Marris, 2001; Rzymski and Królczyk, 2016; Cui and Shoemaker, 2018). The problem is aggravated by past events where misconduct in biotechnology implementation harmed people, e.g. when some medical doctors transferred HIV-contaminated blood to hemophiliacs in mid-80s in France (Kuntz, 2014). Although the issues to handle are not directly related to the older version of GMO, the issues still raise negative sentiment from the public to technology applications on living beings (Marris, 2001). Therefore, the construction of a clear set of rules and ethics in synthetic nucleic acid-based GMO technology should be addressed to gain public trust for its future research and ultimately, the commercial uses.

On a greater scope than application of XNA, there was a team of scientists from J. Craig Venter Institute has 'created' synthetic bacteria which genome is completely synthetic (Gibson et al., 2010). The bacteria were named Mycoplasma mycoides JCVI-syn 1.0, nicknamed "Synthia" (Wang and Zhang, 2019). They assembled the genome by combining thousands of $1 \mathrm{~kb}$ DNA fragments into larger fragments, then transferred it into one to another living cells (such as yeast and E. coli) before finally transferred them into the Mycoplasma. The final synthetic genome consists of designed non-functional "watermark" sequences, designed polymorphism and gene deletions, and acquired mutations. These new cells possess the desired phenotypes and ability for selfreplication (Gibson et al., 2010; Richardson and Patron, 2016). Similar to XNA case, the creation of fullysynthetic life requires clear rules and ethics in the future, especially as such technology will be more accessible in the future and potentially more institutions will be able to conduct the same research. The ethical principles for synthetic life creation include beneficence to the public, responsible stewardship, intellectual freedom and responsibility, democratic deliberation, and justice and fairness (Gutmann, 2011).

It is possible that in the future, as more in vivo experiments are done in greater complexity, the XNA system can be built as an extension of the existing central dogma of DNA-RNA-protein to make a fully synthetic-built life that is fully separated from the naturally occurred life on Earth. The idea of synthetic xenobiology can also be implemented for teaching and the goal is so students can understand that life can be constituted by alternative biomolecules as well as the existing biomolecule extension compounds (Schmitt et al., 2020), hence understanding deeper about the philosophy of life. In the end, if the synthetic life can evolve by itself, it is not impossible that it will rise into a complete unknown xenobiological life as we had referred before (Figure 5). In understanding how life had emerged and evolved in a strange way, especially through speculating and re-creating it synthetically, we may be getting closer to the actual nature and the origin of life. 
In short, "to define alien", we may need to create one first. Deliberate "alienation" of life by synthesis might conform to the second of "three laws" of the famous sci-fi writer Arthur C. Clarke: "The only way of discovering the limits of the possible is to venture a little way past them into the impossible".

\section{Conclusions}

Although xenobiology was once used to describe astrobiology, the term and concept of xenobiology is still relevant to describe and study estranged life forms in many ways. Xenobiology, according to the concept of study of unknown life, is not limited only to space but also to the hidden life on Earth, as well as the advanced synthetic life which are engineered inside the laboratory. Since the foreign life in space is something, we do not know nor able to describe yet, the concept of xenobiology governing the scope for space-borne life (exoxenobiology) is speculative and 'pataphysical'. This would be different on the Terran-xenobiology which specifically covers the hidden life on Earth. Further exploration and research are required to understand life in space, and also ones that were hidden on Earth. Therefore, considering exo-xenobiology perspective, we may try to describe the life in space by "creating" them in hypothetical or speculative pictures. As for the domain of synthetic xenobiology, the life will become more estranged as more unique components are introduced synthetically or by man-made purpose; more significantly estranged later once the synthetic life has evolved on its own in the future.

\section{Authors' Contributions}

Both authors read and approved the final manuscript.

\section{Acknowledgements}

We thank Dr. Markus Schmidt from Biofaction KG, Vienna, Austria for his insight and comments for the figures during the development stage of this paper. Also, to Ganesh Aji Wicaksono (Faculty of Humanities, BINUS University, Jakarta) for his corrections on this paper.

\section{Conflict of Interests}

The authors declare that there are no conflicts of interest related to this article.

\section{References}

Antonovsky N, Gleizer S, Noor E, Zohar Y, Herz E, Barenholz U, ... Milo R (2016). Sugar synthesis from $\mathrm{CO}_{2}$ in Escherichia coli. Cell 166(1):115-125. https://doi.org/10.1016/j.cell.2016.05.064

Ambrogelly A, Palioura S, Söll D (2007). Natural expansion of the genetic code. Nature Chemical Biology 3(1):29-35. https://doi.org/10.1038/nchembio847

Budisa N, Kubyshkin V, Schmidt M (2020). Xenobiology: A Journey towards parallel life forms. Chemistry Europe 22282231. https://doi.org/10.1002/cbic.202000141

Chaput JC, Herdewijn P (2019). What Is XNA? Angewandte Chemie International Edition 58(34):2-5. https://doi.org/10.1002/anie.201905999

Clément G, Slenzka K (2006). Fundamentals of space biology: research on cells, animals, and plants in space (Vol. 18). Springer Science \& Business Media, Heidelberg, Germany. 
Cleland CE, Copley SD (2005). The possibility of alternative microbial life on Earth. International Journal of Astrobiology 4(3-4):165-173. https://doi.org/10.1017/S147355040500279X

Csibra E, Renders M, Pinheiro VB (2020). Towards XNA molecular biology: Bacterial cell display as a robust and versatile platform for the engineering of low affinity ligands and enzymes. bioRxiv.

Cui K, Shoemaker SP (2018). Public perception of genetically-modified (GM) food: A nationwide Chinese consumer study. Science of Food 2(1):1-8. https://doi.org/10.1038/s41538-018-0018-4

Dadachova E, Bryan RA, Huang X, Moadel T, Schweitzer AD, Aisen P, Nosanchuk JD, Casadevall A (2007). Ionizing radiation changes the electronic properties of melanin and enhances the growth of melanized fungi. PloS One 2(5):457. https://doi.org/10.1371/journal.pone.0000457

Dadachova E, Casadevall A (2008). Ionizing radiation: how fungi cope, adapt, and exploit with the help of melanin. Current Opinion in Microbiology 11(6):525-531. https://doi.org/10.1016/j.mib.2008.09.013

Darling D, Schulze-Makuch D (2016). The extraterrestrial encyclopedia. First Edition Design Publishing, New York.

Davies PC, Lineweaver CH (2005). Finding a second sample of life on Earth. Astrobiology 5(2):154-163. https://doi.org/10.1089/ast.2005.5.154

Davies PC, Benner SA, Cleland CE, Lineweaver CH, McKay CP, Wolfe-Simon F (2009). Signatures of a shadow biosphere. Astrobiology 9(2):241-249. https://doi.org/10.1089/ast.2008.0251

Editors of the American Heritage Dictionaries (2011). The American Heritage Dictionary of the English Language. $5^{\text {th }}$ ed. Houghton Mifflin Harcourt, Boston, Massachusetts, USA.

Erb TJ, Kiefer P, Hattendorf B, Günther D, Vorholt JA (2012). GFAJ-1 is an arsenate-resistant, phosphate-dependent organism. Science 337(6093):467-470. https://doi.org/10.1126/science.1218455

Galindo-Murillo R, Barroso-Flores J (2017). Structural and dynamical instability of DNA caused by high occurrence of d5SICS and dNaM unnatural nucleotides. Physical Chemistry Chemical Physics 19(16):10571-10580. https://doi.org/10.1039/C7CP01477E

Gibson DG, Glass JI, Lartigue C, Noskov VN, Chuang RY, Algire MA, ... Merryman C (2010). Creation of a bacterial cell controlled by a chemically synthesized genome. Science 329(5987):52-56. https://doi.org/10.1126/science.1190719

Gleizer S, Ben-Nissan R, Bar-On YM, Antonovsky N, Noor E, Zohar Y, ...Milo R (2019). Conversion of Escherichia coli to generate all biomass carbon from $\mathrm{CO}_{2}$. Cell 179(6):1255-1263. https://doi.org/10.1016/j.cell.2019.11.009

Gutmann A (2011). The ethics of synthetic biology: guiding principles for emerging technologies. Hastings Center Report 41(4):17-22. https://doi.org/10.1002/j.1552-146X.2011.tb00118.X

Hanson R (1998). The great filter: Are we almost past it? Retrieved 2021 June 01 from https://web.archive.org/web/20100507074729/http://hanson.gmu.edu/greatfilter.html

Haque RU, Paradisi F, Allers T (2020). Haloferax volcanii for biotechnology applications: challenges, current state and perspectives. Applied Microbiology and Biotechnology 104(4):1371-1382. https://doi.org/10.1007/s00253019-10314-2

Hawking S (1996). Life in the universe. Retrieved 2021 June 01 from https://www.hawking.org.uk/inwords/lectures/life-in-the-universe

Herdewijn P, Marlière P (2009). Toward safe genetically modified organisms through the chemical diversification of nucleic acids. Chemistry \& Biodiversity 6(6):791-808. https://doi.org/10.1002/cbdv.200900083

Hielscher S, Pies I, Valentinov V, Chatalova L (2016). Rationalizing the GMO debate: The ordonomic approach to addressing agricultural myths. International Journal of Environmental Research and Public Health 13(5):476. http://dx.doi.org/10.3390/ijerph13050476

Horneck G, Rettberg P, Reitz G, Wehner J, Eschweiler U, Strauch K, ... Baumstark-Khan C (2001). Protection of bacterial spores in space, a contribution to the discussion on panspermia. Origins of Life and Evolution of the Biosphere 31(6):527-547. https://doi.org/10.1023/A:1012746130771

Hugill A (2012). Pataphysics: a useless guide. MIT Press, Massachusetts, USA.

Impey C (2011). The living cosmos: our search for life in the universe. Cambridge University Press, Cambridge, UK, pp 189.

Karnkowska A, Vacek V, Zubáčová Z, Treitli SC, Petrželková R, Eme L, ... Soukal P (2016). A eukaryote without a mitochondrial organelle. Current Biology 26(10):1274-1284. https://doi.org/10.1016/j.cub.2016.03.053

Karalis DT, Karalis T, Karalis S, Kleisiari AS (2020). Genetically modified products: perspectives and challenges. Cureus 12(3):e7306. https://doi.org/10.7759/cureus.7306 
Kim JI, Cox MM (2002). The RecA proteins of Deinococcus radiodurans and Escherichia coli promote DNA strand exchange via inverse pathways. Proceedings of the National Academy of Sciences USA 99(12):7917-7921. https://doi.org/10.1073/pnas.122218499

Krzmarzick MJ, Taylor DK, Fu X, McCutchan AL (2018). Diversity and niche of archaea in bioremediation. Archaea 2018:3194108. https://doi.org/10.1155/2018/3194108

Kubyshkin V, Budisa N (2017). Synthetic alienation of microbial organisms by using genetic code engineering: Why and how? Biotechnology Journal 12(8):1600097. https://doi.org/10.1002/biot.201600097

Kuntz M (2014). The GMO case in France: politics, lawlessness and postmodernism. GM Crops \& Food 5(3):163-169. https://doi.org/10.4161/21645698.2014.945882

Kuznetsov SI (1956). Possibility of radiosynthesis. Mikrobiologiia 25(2):195-199.

Kvenvolden K, Lawless J, Pering K, Peterson E, Flores J, Ponnamperuma C, Kaplan IR, Moore C (1970). Evidence for extra-terrestrial amino-acids and hydrocarbons in the Murchison meteorite. Nature 228(5275):923-926. https://doi.org/10.1038/228923aO

Lodders K (2010). Exoplanet chemistry. In: Barnes R (Ed). Formation and Evolution of Exoplanets. Glasgow, John Wiley \& Sons, pp 169.

Malo ME, Dadachova E (2019) Melanin as an energy transducer and a radioprotector in black fungi. In: Tiquia-Arashiro S, Grube M (Eds). Fungi in Extreme Environments: Ecological Role and Biotechnological Significance. Springer, Cham. https://doi.org/10.1007/978-3-030-19030-9_10

Malyshev DA, Dhami K, Lavergne T, Chen T, Dai N, Foster JM, Corrêa IR, Romesberg FE (2014). A semi-synthetic organism with an expanded genetic alphabet. Nature 509(7500):385-388. https://doi.org/10.1038/nature13314

Marris C (2001). Public views on GMOs: deconstructing the myths. Stakeholders in the GMO debate often describe public opinion as irrational. But do they really understand the public?. EMBO Reports 2(7):545-548. https://doi.org/10.1093/embo-reports/kve142

Martins Z, Botta O, Fogel ML, Sephton MA, Glavin DP, Watson JS, ... Ehrenfreund P (2008). Extra-terrestrial nucleobases in the Murchison meteorite. Earth and Planetary Science Letters 270(1-2):130-136. https://doi.org/10.1016/j.epsl.2008.03.026

Mix LJ (2009). Life in space: astrobiology for everyone. Harvard University Press, Massachusetts, USA pp 4-5.

Miller TE, Beneyton T, Schwander T, Diehl C, Girault M, McLean R, ... Erb TJ (2020). Light-powered $\mathrm{CO}_{2}$ fixation in a chloroplast mimic with natural and synthetic parts. Science 368(6491):649-654. https://doi.org/10.1126/science.aaz6802

Muller AW, Schulze-Makuch D (2006). Thermal energy and the origin of life. Origins of Life and Evolution of Biospheres 36(2):177-189. https://doi.org/10.1007/s11084-005-9003-4

Mursidawati S, Wicaksono A, Teixeira da Silva JAT (2019). Development of the endophytic parasite, Rafflesia patma Blume, among host plant (Tetrastigma leucostaphylum (Dennst.) Alston) vascular cambium tissue. South African Journal of Botany 123:382-386. https://doi.org/10.1016/j.sajb.2019.03.028

Nikolov LA, Tomlinson PB, Manickam S, Endress PK, Kramer EM, Davis CC (2014). Holoparasitic Rafflesiaceae possess the most reduced endophytes and yet give rise to the world's largest flowers. Annals of Botany 114(2):233-242. https://doi.org/10.1093/aob/mcu114

Pinheiro VB, Taylor AI, Cozens C, Abramov M, Renders M, Zhang S, ... Herdewijn P (2012). Synthetic genetic polymers capable of heredity and evolution. Science 336(6079):341-344. https://doi.org/10.1126/science.1217622

Popa R (2010). Necessity, futility and the possibility of defining life are all embedded in its origin as a punctuatedgradualism. Origins of Life and Evolution of Biospheres 40(2):183-190. https://doi.org/10.1007/s11084-0109198- $x$

Reaves ML, Sinha S, Rabinowitz JD, Kruglyak L, Redfield RJ (2012). Absence of detectable arsenate in DNA from arsenate-grown GFAJ-1 cells. Science 337(6093):470-473. https://doi.org/10.1126/science.1219861

Richardson SM, Patron NJ (2016). Synthia: playing god in a sandbox. Retrieved 2020 August 20 from https://microbiologysociety.org/publication/past-issues/what-is-life/article/synthia-playing-god-in-asandbox-what-is-life.html

Rzymski P, Królczyk A (2016). Attitudes toward genetically modified organisms in Poland: to GMO or not to GMO?. Food Security 8:689-697. https://doi.org/10.1007/s12571-016-0572-z

Sagan C, Salpeter EE (1976). Particles, environments, and possible ecologies in the Jovian atmosphere. The Astrophysical Journal Supplement Series 32:737-755. 
Schmidt M (2010). Xenobiology: a new form of life as the ultimate biosafety tool. Bioessays 32(4):322-331. https://doi.org/10.1002/bies.200900147

Schmitt-Kopplin P, Gabelica Z, Gougeon RD, Fekete A, Kanawati B, Harir M, Gebefuegi I, ... Hertkorn N (2010). High molecular diversity of extra-terrestrial organic matter in Murchison meteorite revealed 40 years after its fall. Proceedings of the National Academy of Sciences USA 107(7):2763-2768. https://doi.org/10.1073/pnas.0912157107

Schmitt FJ, Frielingsdorf S, Friedrich T, Budisa N (2021). Courses based on iGEM/BIOMOD competitions are the ideal format for research-based learning of xenobiology. Chemistry Europe 22(5):818-825. https://doi.org/10.1002/cbic.202000614

Schulze-Makuch D, Irwin LN (2002). Energy cycling and hypothetical organisms in Europa's ocean. Astrobiology 2(1):105-121. https://doi.org/10.1089/153110702753621385

Schulze-Makuch D, Irwin LN (2018). Life in the universe: Expectations and Constraints $3^{\text {rd }}$ ed. Springer Science \& Business Media, Heidelberg, Germany.

Stavropoulos DN, Hornby AS (2008). Oxford English-Greek Learner's Dictionary. $2^{\text {nd }}$ ed. Oxford University Press, Oxford, UK.

Stoeckenius W (1981). Walsby's square bacterium: fine structure of an orthogonal procaryote. Journal of Bacteriology $148(1): 352-360$.

Taylor AI, Holliger P (2015). Directed evolution of artificial enzymes (XNAzymes) from diverse repertoires of synthetic genetic polymers. Nature Protocols 10(1):1625-1642. https://doi.org/10.1038/nprot.2015.104

Taylor AI, Pinheiro VB, Smola MJ, Morgunov AS, Peak-Chew S, Cozens C, ... Holliger P (2015). Catalysts from synthetic genetic polymers. Nature 518(7539):427-430. https://doi.org/10.1038/nature13982

Wagner I, Musso H (1983). New naturally occurring amino acids. Angewandte Chemie International Edition in English 22(11):816-828. https://doi.org/10.1002/anie.198308161

Walton, D. (2010). Space rock contains organic molecular feasts. Retrieved 2021 May 31 from https://web.archive.org/web/20100216052616/http://news.bbc.co.uk/2/hi/science/nature/8516319.stm

Wang F, Zhang W (2019). Synthetic biology: recent progress, biosafety and biosecurity concerns, and possible solutions. Journal of Biosafety and Biosecurity 1(1):22-30. https://doi.org/10.1016/j.jobb.2018.12.003

Ward P, Brownlee D (2000). Rare earth: why complex life is uncommon in the universe. Copernicus Book, New York, USA.

Wolfe-Simon F, Blum JS, Kulp TR, Gordon GW, Hoeft SE, Pett-Ridge J, ... Anbar AD (2011). A bacterium that can grow by using arsenic instead of phosphorus. Science 332(6034):1163-1166. https://doi.org/10.1126/science.1197258

Yahalomi D, Atkinson SD, Neuhof M, Chang ES, Philippe H, Cartwright P, ... Huchon D (2020). A cnidarian parasite of salmon (Myxozoa: Henneguya) lacks a mitochondrial genome. Proceedings of the National Academy of Sciences USA 117(10):5358-5363. https://doi.org/10.1073/pnas.1909907117

Zhdanova NN, Vasilevskaya AI, Artyshkova LV, Sadovnikov YS, Lashko TN, Gavrilyuk VI, Dighton J (1994). Changes in micromycete communities in soil in response to pollution by long-lived radionuclides emitted in the Chernobyl accident. Mycological Research 98(7):789-795. https://doi.org/10.1016/S0953-7562(09)81057-5

Zhdanova NN, Tugay T, Dighton J, Zheltonozhsky V, Mcdermott P (2004). Ionizing radiation attracts soil fungi. Mycological Research 108(9):1089-1096. https://doi.org/10.1017/S0953756204000966
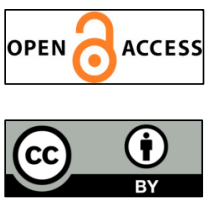

The journal offers free, immediate, and unrestricted access to peer-reviewed research and scholarly work. Users are allowed to read, download, copy, distribute, print, search, or link to the full texts of the articles, or use them for any other lawful purpose, without asking prior permission from the publisher or the author.

License - Articles published in Notulae Scientia Biologicae are Open-Access, distributed under the terms and conditions of the Creative Commons Attribution (CC BY 4.0) License.

(c) Articles by the authors; SHST, Cluj-Napoca, Romania. The journal allows the author(s) to hold the copyright/to retain publishing rights without restriction. 